\title{
Recurrent Postpartum Thyroiditis in a Patient With Chronic Autoimmune Thyroiditis: A Case Report
}

\author{
Young Sik Choi ${ }^{\mathrm{a}, \mathrm{d}}$, Bu Kyoung Kimª , Su Kyung Kwon ${ }^{\mathrm{a}}$, Yo-Han Park ${ }^{\mathrm{a}}$, \\ Jeong Hoon Kim ${ }^{\mathrm{b}}$, Eun Hee Kong ${ }^{\mathrm{c}}$
}

\begin{abstract}
Postpartum thyroiditis is a destructive thyroiditis induced by an autoimmune mechanism that begins within the first few months after delivery. Postpartum thyroiditis can also occur after spontaneous abortion, here we report three documented episodes of recurrent postpartum thyroiditis, one of which developed after pregnancy loss. Our patient is a 33-year-old woman who complained of discomfort with palpitations two months after her first delivery. Laboratory examination of thyroid function tests (TFT) revealed transient hyperthyroidism followed by hypothyroidism and then recovery (a classic triphasic pattern). Two years later, the patient suffered a spontaneous abortion of her second pregnancy at 16 weeks gestation. Three months after the loss of this second pregnancy, TFT showed the classic triphasic pattern again. Two years following the spontaneous abortion, the patient gave birth to her second child, and three months after delivery, the patient complained of heat intolerance and irritability. Laboratory tests during this time showed an elevated FT4 and a low TSH. Tc-99m scintigraphy showed nonvisualization of both thyroid lobes, and 24-hour radioactive iodine uptake was $0.2 \%$. This patient in this case presented with the classic triphasic pattern in all three episodes.
\end{abstract}

Keywords: Recurrent postpartum thyroiditis; Abortion; Chronic autoimmune thyroiditis

\footnotetext{
Manuscript accepted for publication January 3, 2013

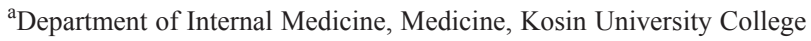
of Medicine, Busan, Korea

${ }^{\mathrm{b}}$ Department of General Surgery, Medicine, Kosin University College of Medicine, Busan, Korea

${ }^{c}$ Department of Family Medicine, Kosin University College of Medicine, Busan, Korea

${ }^{\mathrm{d} C}$ Corresponding author: Young Sik Choi, Department of Internal Medicine, Kosin University College of Medicine, 34 Amnam-dong, Seo-gu, Busan, 602-702, Korea. Email: yschoi@kosinmed.or.kr
}

doi: http://dx.doi.org/10.4021/jmc1060w

\section{Introduction}

Postpartum thyroiditis is a destructive inflammation of the thyroid that is induced by an autoimmune mechanism within the first few months after delivery. After one episode of postpartum thyroiditis, there is a 70 percent chance of recurrence with subsequent pregnancies [1]. There has previously been a case that reported recurrent postpartum thyroiditis after each of three pregnancies [2]. The risk of spontaneous abortion in thyroid antibody-positive women is two- to four-fold greater than in antibody-negative women [3]. Postpartum thyroiditis can also occur after spontaneous or induced abortion [4], but a case of three documented episodes of postpartum thyroiditis, one of which developed after a spontaneous abortion, in a single patient has not yet been reported in the literature.

In this article, we report a patient with recurrent postpartum thyroiditis after each of three pregnancies, one of which developed after a spontaneous abortion.

\section{Case Report}

A 33-year-old woman was referred to our clinic for treatment of chronic autoimmune thyroiditis. She was diagnosed with hypothyroidism with goiter at a local medical clinic and treated intermittently with levothyroxine. Physical examination of the neck revealed a diffusely enlarged and non-tender thyroid gland. Ultrasonography (US) was carried out using a real-time linear array $10 \mathrm{MHz}$ transducer. The thyroid US demonstrated a diffusely enlarged thyroid gland with a 0.3 $\times 0.4 \mathrm{~cm}$ hypoechoic nodule in the right thyroid. The serial change in thyroid function tests (TFT) and the titer of autoantibodies over time are summarized in Table 1.

The patient gave birth to her first child. About one year before delivery, the results of a TFT were within normal limits with an increased titer of thyroid autoantibodies (Table 1). Two months after delivery, the patient complained of feeling unwell with palpitations. Laboratory examination showed that $\mathrm{T} 3$ was $331.6 \mathrm{pg} / \mathrm{mL}$, (normal range: $65-181 \mathrm{pg} / \mathrm{mL}$ ), thyroid-stimulating hormone (TSH) was $0.009 \mu \mathrm{IU} / \mathrm{L}$ (normal range: $0.35-5.50 \mu \mathrm{IU} / \mathrm{L}$ ), free thyroxine (FT4) was 3.76 
ng/dL (normal range: 0.89 - $1.76 \mathrm{ng} / \mathrm{dL}$ ), antithyroglobulin was $39.0 \mathrm{U} / \mathrm{mL}$ (negative $<60 \mathrm{U} / \mathrm{mL}$ ), antimicrosomal antibodies were $167.4 \mathrm{U} / \mathrm{mL}$ (negative $<60 \mathrm{U} / \mathrm{mL}$ ), and thyrotropin-binding inhibitory immunoglobulin (TBII) was $<1$ $\mathrm{U} / \mathrm{L}$ (normal range: 0 - $10 \mathrm{U} / \mathrm{L}$ ). Two months later, her TSH was $61.764 \mu \mathrm{IU} / \mathrm{L}$ and she was started on levothyroxine. Five month later, her TSH level returned to a normal range and levothyroxine was stopped.

The patient lost her second pregnancy to spontaneous abortion at 16 weeks of gestation. The patient had not been taking levothyroxine before conception or at the time of miscarriage. Three months after pregnancy loss, TFT revealed that T3 was $206.3 \mathrm{pg} / \mathrm{mL}$, TSH was $0.273 \mu \mathrm{IU} / \mathrm{L}$, and FT4 was $1.63 \mathrm{ng} / \mathrm{dL}$. Two months later, her TSH level and titer of autoantibodies were markedly increased. She was restarted on levothyroxine and remained euthyroid (Table 1). Her second child was born. During this third pregnancy, she was taking levothyroxine and her thyroid function remained normal throughout. Three months after delivery, the patient complained of heat intolerance and irritability. Laboratory tests showed an elevated FT4 and a low TSH (Table 1). Tc-

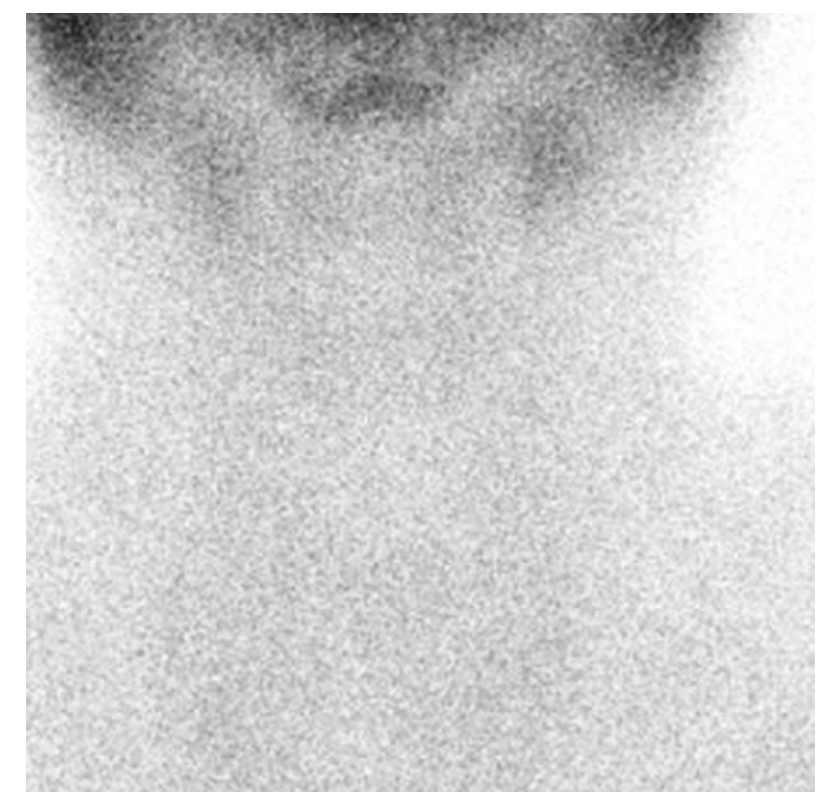

Figure 1. Tc- 99m scintigraphy shows nonvisualization of both thyroid lobes.

Table 1. Serial Change in Thyroid Function Tests and Autoantibody Titers

\begin{tabular}{|c|c|c|c|c|c|}
\hline Date & $\begin{array}{l}\text { T3 } \\
(65-181 \mathrm{pg} / \mathrm{mL})\end{array}$ & $\begin{array}{l}\text { TSH } \\
(0.35-5.50 \mu \mathrm{IU} / \mathrm{L})\end{array}$ & $\begin{array}{l}\text { FT4 } \\
(0.89-1.76 \mathrm{ng} / \mathrm{dL})\end{array}$ & $\begin{array}{l}\text { Anti Tg Ab } \\
(<60 \mathrm{U} / \mathrm{mL})\end{array}$ & $\begin{array}{l}\text { Anti MS Ab } \\
(<60 \mathrm{U} / \mathrm{mL})\end{array}$ \\
\hline \multicolumn{6}{|c|}{ Before pregnancy } \\
\hline 7 Mar 2005 & 138.3 & 3.941 & 1.31 & 347.7 & $>1,300$ \\
\hline \multicolumn{6}{|c|}{ 1st event (Birth date; 6 Jan 2006) } \\
\hline 24 Mar 2006 & 331.6 & 0.009 & 3.76 & 39.0 & 167.4 \\
\hline 17 May 2006 & 100.5 & 61.764 & 0.63 & & \\
\hline 17 Aug 2006 & 111.5 & 1.483 & 1.28 & & \\
\hline 27 Feb 2007 & 138.5 & 0.025 & 1.27 & & \\
\hline \multicolumn{6}{|c|}{ 2nd event (Abortion date; 19 Jan 2008) } \\
\hline 2 Apr 2008 & 206.3 & 0.273 & 1.63 & 486.6 & 484.8 \\
\hline 10 Jun 2008 & 105.4 & 118.591 & 0.44 & $>500$ & $>1,300$ \\
\hline 21 Oct 2008 & 116.3 & 2.145 & 1.10 & & \\
\hline 24 Feb 2009 & 131.6 & 2.059 & 1.35 & $>500$ & 653.2 \\
\hline \multicolumn{6}{|c|}{ 3rd event (Birth date; 20 Apr 2010) } \\
\hline 20 Jun 2010 & 217.0 & 0.006 & 2.28 & & \\
\hline 9 Sep 2010 & 121.5 & 106.345 & 0.40 & & \\
\hline 16 Nov 2010 & 97.3 & 1.227 & 1.16 & & \\
\hline 16 Mar 2011 & 93.6 & 0.992 & 1.07 & & \\
\hline 7 Mar 2012 & 100.1 & 1.497 & 1.18 & 196.8 & $>1,300$ \\
\hline
\end{tabular}

TSH: thyroid stimulating hormone; Anti Tg Ab: antithyroglobulin antibody; Anti MS Ab: antimicrosomal antibody. 
$99 \mathrm{~m}$ scintigraphy showed nonvisualization of both thyroid lobes, and 24-hour radioactive iodine uptake was $0.2 \%$ (Fig. 1 ), which suggested destructive thyroiditis. The patient was treated with a beta-blocker during this thyrotoxic period. During this thyrotoxic event, she developed postpartum thyroiditis with hyperthyroidism followed by hypothyroidism with an eventual return to normal thyroid function (Table 1).

\section{Discussion}

Postpartum thyroiditis causes lymphocytic inflammation of the thyroid within the first few months after delivery, and the prevalence of postpartum thyroiditis in iodine-sufficient areas ranges between 5-7\% [5]. The disease is most common in women who have a high serum thyroid peroxidase antibody concentration during the first trimester of pregnancy or immediately after delivery [6] and in patients with a previous history of postpartum thyroiditis [1,7]. The present case is of a woman living in Korea, which is an iodine-sufficient area [8]. The patient also had high titer of thyroid autoantibodies with a previous history of postpartum thyroiditis. Postpartum thyroiditis usually presents in one of three ways: transient hyperthyroidism alone, transient hypothyroidism alone, or transient hyperthyroidism followed by hypothyroidism and then recovery. Stagnaro-Green [9] reported that hypothyroidism occurs in 43 percent of patients before the recovery phase, hyperthyroidism in 32 percent, and hyperthyroidism followed by hypothyroidism in 25 percent. Only one-third of patients with postpartum thyroiditis develop the classic triphasic thyroid hormone pattern of transient hyperthyroidism followed by hypothyroidism and then recovery [6], which the present case exhibited in all three episodes. Hyperthyroidism usually occurs two to ten months after delivery, most commonly at three months, with recovery taking place over the next two to three months [10]. In the present patient, hyperthyroidism occurred two to three months after delivery. Hypothyroidism occurs between two and 12 months after delivery, most commonly at six months [10], and in the present case, hyperthyroidism occurred four to five months after delivery. Most patients have normal thyroid function at one year [10], and all three episodes in the present case recovered within one year.

Abortion is a common clinical problem, and several studies have revealed a strong correlation between presence of thyroid antibodies and spontaneous abortion [11-13]. Bagis et al [3] reported that 50\% of thyroid autoantibody-positive women and $14.1 \%$ of thyroid autoantibody-negative patients had a history of spontaneous abortion. Othman et al [14] found that patients with postpartum thyroiditis and persistent hypothyroidism had a higher rate of spontaneous abortion than those patients who returned to a euthyroid state. In the present case, the patient was thyroid autoantibody-positive with postpartum thyroiditis. Therefore, both of these factors could have influenced the spontaneous abortion. There have been many other reports of postpartum thyroiditis that have developed after pregnancy loss $[4,15,16]$. Postpartum thyroiditis that develops after abortion may also be associated with presence of thyroid autoantibodies [4].

In summary, patients with postpartum thyroiditis with presence of thyroid autoantibodies have an increased risk of recurrence of thyroiditis and spontaneous abortion. Therefore, patients with postpartum thyroiditis should be carefully assessed during all pregnancies following the first instance of thyroiditis.

\section{References}

1. Lazarus JH, Ammari F, Oretti R, Parkes AB, Richards CJ, Harris B. Clinical aspects of recurrent postpartum thyroiditis. Br J Gen Pract. 1997;47(418):305-308.

2. Gay JL, Nash ML. Recurrent postpartum painless thyroiditis. South Med J. 1980;73(12):1674-1675.

3. Bagis T, Gokcel A, Saygili ES. Autoimmune thyroid disease in pregnancy and the postpartum period: relationship to spontaneous abortion. Thyroid. 2001;11(11):10491053.

4. Marqusee E, Hill JA, Mandel SJ. Thyroiditis after pregnancy loss. J Clin Endocrinol Metab. 1997;82(8):24552457.

5. Muller AF, Drexhage HA, Berghout A. Postpartum thyroiditis and autoimmune thyroiditis in women of childbearing age: recent insights and consequences for antenatal and postnatal care. Endocr Rev. 2001;22(5):605-630.

6. Pearce EN, Farwell AP, Braverman LE. Thyroiditis. N Engl J Med. 2003;348(26):2646-2655.

7. Nicholson WK, Robinson KA, Smallridge RC, Ladenson PW, Powe NR. Prevalence of postpartum thyroid dysfunction: a quantitative review. Thyroid. 2006;16(6):573-582.

8. Cho YW, Kim YS, Baick SH, Oh DY, Kim WJ, Kang MW, Kim KS. Analysis of Daily Intake and Urinary Excretion of Iodine normal Control and Patient with Thyroid Disease. J Kor Soc Endocrinol. 1994;9(4):307-317.

9. Stagnaro-Green A. Clinical review 152: Postpartum thyroiditis. J Clin Endocrinol Metab. 2002;87(9):40424047.

10. Bindra A, Braunstein GD. Thyroiditis. Am Fam Physician. 2006;73(10):1769-1776.

11. Rajatanavin R, Chailurkit LO, Tirarungsikul K, Chalayondeja W, Jittivanich U, Puapradit W. Postpartum thyroid dysfunction in Bangkok: a geographical variation in the prevalence. Acta Endocrinol (Copenh). 1990;122(2):283-287.

12. Singh A, Dantas ZN, Stone SC, Asch RH. Presence of thyroid antibodies in early reproductive failure: biochemical versus clinical pregnancies. Fertil Steril. 
1995;63(2):277-281.

13. Iijima T, Tada H, Hidaka Y, Mitsuda N, Murata Y, Amino N. Effects of autoantibodies on the course of pregnancy and fetal growth. Obstet Gynecol. 1997;90(3):364-369.

14. Othman S, Phillips DI, Parkes AB, Richards CJ, Harris B, Fung H, Darke C, et al. A long-term follow-up of postpartum thyroiditis. Clin Endocrinol (Oxf).
1990;32(5):559-564.

15. Amino N, Miyai K, Kuro R, Tanizawa O, Azukizawa M, Takai S, Tanaki F, et al. Transient postpartum hypothyroidism: fourteen cases with autoimmune thyroiditis. Ann Intern Med. 1977;87(2):155-159.

16. Stagnaro-Green A. Post-miscarriage thyroid dysfunction. Obstet Gynecol. 1992;80(3 Pt 2):490-492. 